\title{
PENGARUH LATIHAN TUCK JUMP TERHADAP PENINGKATAN TINGGI LOMPATAN PEMAIN BOLA VOLI PUTRA SMA ITP SURABAYA
}

\author{
Shandy Pieter ${ }^{1}$, Riston Sabealu ${ }^{2}$ \\ Pedagogik dan Psikologi,Universitas PGRI Adi Buana Surabaya \\ shandypieter.or@gmail.com, ristonsabelau@gmail.com
}

\begin{tabular}{l}
\hline Artikel Info \\
\hline Koresponden penulis: \\
Shandy Pieter \\
Email: \\
shandypieter.or@gmail.com \\
\\
$\square$ Diterima 30 Oktober 2020 \\
$\square$ Direview 31 Oktober 2020 \\
$\square$ Disetujui 31 Oktober 2020 \\
$\square$ Dipublikasi 31 Oktober 2020
\end{tabular}

Kata Kunci:

Tuck jump, tinggi lompatan

Keywords:

Tuck Jump, Jump Height

\begin{abstract}
Abstrak
Penelitian ini memfokuskan kebutuhan data di lapangan yaitu kurangnya kemampuan pemain bola voli tinggi dalam melompat. Kurangnya pelatihan lompat tinggi khusus adalah salah satu faktor utama. Dengan tambahan pelatihan Tuck Jump untuk pemain bola voli putra, terjadi peningkatan ketinggian lompatan. Penelitian menggunakan metode kuantitatif. Populasi dalam penelitian ini adalah pemain bola voli putra SMA Intensif Taruna Pembangunan Surabaya di Surabaya. Sampel yang digunakan sebanyak 20 orang dengan membagi 10 kelompok eksperimen dan 10 kelompok kontrol. Hasil penelitian menunjukkan pengaruh yang signifikan 5\% $(a=0,05)$, tabel $t$ hitung 2,86> $t$ tabel 1,73. Artinya nilai $t$ hitung diterima. Dapat disimpulkan bahwa keberadaan latihan Tuck Jump sangat berpengaruh terhadap tinggi lompatan pemain bola voli putra SMA Intensif Taruna Pembangunan Surabaya.
\end{abstract}

\begin{abstract}
This research is focused on the data needs in the field, namely the ability of the ball player who is the deepest. The lack of specific training height jumps is one of the main factors. With the addition of Tuck Jump training for men's volleyball players, there is an increase in jump height. Research using quantitative methods. The population in this study is the male volleyball player of Surabaya Intensive Development School in Surabaya. The sample used was 20 people by dividing 10 experimental groups and 10 control groups. The results showed a significant influence of 5\% $(a=0,05)$, namel t count 2,86 >t table 1,73. This means that the calculated t value is accepeted. It can be concluded that the existence of Tuck Jump training is very influential on the height of men's volleyball players jumpng from Surabaya Intensive Development Team
\end{abstract}




\begin{tabular}{|c|c|c|}
\hline Unipa Sunalaga & $\begin{array}{l}\text { Journal STAND: Sports and Development } \\
\text { http://jurnal.unipasby.ac.id/index.php/stand/about/submissions } \\
\text { jurnal.stand@unipasby.ac.id }\end{array}$ & $G 7$ \\
\hline
\end{tabular}

\section{PENDAhULUAN}

Olahraga adalah kegiatan terbuka bagi semua orang sesuai dengan kemampuan, kesenangan dan kesempatan menurut Rosdiani (2012:62). Adapun menurut (Graurav, Singh 2010:3) permainan bola voli adalah permainan yang menggunakan bola termasuk bola voli membutuhkan kemampuan yang bersifat komprehensif termasuk fisik, teknik, mental dan strategi. Permainan Bola Voli adalah salah satu dari permainan bola besar yang dilakukan oleh banyak orang dan sudah menguasai peraturan, taktik permainan serta teknik dasar .beberapa teknik dasar dalam permainan ini yang harus dikuasai adalah: 1.Servis, 2.Pasing, 3.Spike, 4.Blok.

Dikalangan masyarakat bola voli dikenal secara luas, dan begitupun pada atlet pemain bola voli putra juga sangat diminati. Namun sangat disayangkan bahwa kurangnya melatih diri dalam melakukan teknik lompatan pada saat melakukan smash. Akibatnya pada saat pertandingan tidak dapat mencapai hasil yang maksimal.

Oleh sebab dengan adanya latihan Tuck Jump dapat diterapkan dikalangan manapun terutama pada atlet pemain bola voli putra agar dapat meningkatkan kemampuan pada tinggi lompatan.

Latihan menurut Bompa dan Haff (2009:2) adalah proses dimana seorang siswa dipersiapkan untuk meningkatkan peformanya setinggi mungkin. Dalam latihan juga harus memiliki tujuan dimana akan diaplikasikan pada kompetisi-kompetisi nantinya manghasilkan prestasi yang maksimal.

Berdasarkan paparan diatas latihan merupakan tindakan wajib yang harus dilakukan oleh seorang atlet untuk meningkatkan kemampuan teknik berolahraga. Dengan adanya latihan atlet siap dalam mengikuti suatu pertandingan atau kompetisikompetisi.

Tuck jump menurut (Herrington et al, 2013:155) merupakan salah satu bentuk latihan yang bisa dilakukan dimana saja tanpa menggunakan alat dan sebagai beban latihan adalah tubuh sendiri. Gerakan ini mudah untuk dilakukan tetapi membutuhkan tingkat usaha yang tinggi dari seorang atlet karena harus melompat semaksimal mungkin sampai kaki mengarah ke dada.

Berdasarkan pendapat diatas Tuck jump merupakan latihan yang dapat dilakukan dengan cara sederhana yang bertumpu pada beban tubuh sendiri. Cara melakukan Tuck jump dengan cara berdiri, kaki dibuka selebar bahu kemudian lompat ke atas secara eksplosif.

Manfaat penelitian ini membantuh para pelatih dalam mengembangkan metode latihan Tuck Jump yang sesuai dengan permainan bola voli, menjadi bahan referensi khusunya bagi Pembina dan pelatih ekstrakurikuler bola voli dalam menerapkan metode latihan, sehingga akan lebih efektif dan efesien, serta Sebagai sarana untuk memperoleh sejauh mana teori yang diajarkan dan dipelajari sesuai dengan prakteknya dilapangan.

Volume 1 Nomor 2 Tahun 2020| 138 
http://jurnal.unipasby.ac.id/index.php/stand/about/submissions jurnal.stand@unipasby.ac.id

\section{METODE PENELITIAN}

Desain digunakan utnuk mengetahui adanya pengaruh latihan Tuck Jump terhadap peningkatan tinggi lompatan pada pemain bola voli putra. Dalam penelitian ini, menggunakan jenis penelitian Pretest-Posttest Control Grup Design.

Pretest-Posttest Control Grup Design menurut Sugiyono (2016:112) adalah dua kelompok yang dipilih secara random, kemudian diberi pretes untuk mengetahui keadaan awal, adakah perbedaan antara kelompok eksperimen dan kelompok control. Hasil pretes yang baik apabila nilai kelompok eksperimen tidak berbeda secara signifikan. Pengaruh perlakuan adalah $\left(0 \_2-O \_1\right)-$ (O_4-O_3).

$$
\begin{array}{llll}
\mathrm{R} & O_{1} & \mathrm{X} & O_{2} \\
\mathrm{R} & O_{3} & \mathrm{X} & O_{4}
\end{array}
$$

Populasi Menurut (Maksum,2009) adalah seluruh objek atau individu yang dimaksudkan untuk diteliti ada yang nantinya akan dikenai generalisasi. populasi yang digunakan ialah pemain bola voli putra di SMA Intensif Taruna Pembangunan Surabaya yang berjumlah 20 orang putra.

Sampel menurut (Arikunto, 2006:131) adalah sebagian atau wakil populasi yang diteliti. Sampel merupakan objek dari bagian kecil populasi. Sampel ini menggunakan 10 orang untuk kelompok control dan 10 orang kelompok eksperimen.

Pengumpulan data menurut (Ali Maksum, 2009:54) adalah proses pengadaan data baik primer maupun sekunder untuk kepentingan penelitian.

Berdasarkan paparan diatas teknik pengumpulan data sangat penting dalam menguji hipotesis. Teknik yang digunakan ialah tes dan pengukuran. Tes pretes untuk mengetahui keterampilan tinggi lompatan, kemudian postes untuk mengetahui seberapa besar pengaruh latihan Tuck Jump terhadap tinggi lompatan.

teknik analisis data menurut (Sunarno dan Sihombing, 2011) baik buruknya analisis data sangat tergantung pada data yang dikumpulkan, baiknya data yang terkumpul sangat tergantung pada baiknya instrumen penelitian. Maka teknik analisis data adalah teknik yang digunakan untuk mengelolah data penelitian.

Pada penelitian ini teknik analisis data menggunakan rumus t-test untuk sampel, Adapun rumus yang dimaksud adalah:

$$
t=\frac{\sum D}{\frac{\sqrt{N \sum D^{2}-\left(\Sigma^{D}\right)^{2}}}{N-1}}
$$

Keterangan :

$\mathrm{D}=$ Perbedaan setiap pasangan skor ( pretespostest).

$\mathrm{N}=$ Jumlah sampel. 


\section{Journal STAND: Sports and Development}

http://jurnal.unipasby.ac.id/index.php/stand/about/submissions jurnal.stand@unipasby.ac.id

\section{HASIL DAN PEMBAHASAN}

Dalam penelitian ini penulis akan menyajikan data yang terkumpul secara konkrit dan empiris didalam lapangan melalui tes dan pengukuran yang dilakukan oleh anggota sampel dalam penelitian.

Dari program latihan diatas maka mendpatkan data berupa angka. Berikut Data yang telah terkumpul ialah:

Tabel 1. Data hasil pretest dan posttest kelompok eksperimen

\begin{tabular}{|c|c|c|c|c|c|}
\hline \multirow{2}{*}{ No } & \multirow{2}{*}{ Nama } & \multicolumn{2}{|c|}{$\begin{array}{l}\text { Tes Tinggi } \\
\text { Lompatan }\end{array}$} & \multirow{2}{*}{$\begin{array}{c}\text { Beda } \\
(\mathrm{x})\end{array}$} & \multirow{2}{*}{$x^{2}$} \\
\hline & & $\begin{array}{c}\text { Pret } \\
\text { est }\end{array}$ & $\begin{array}{l}\text { Pos } \\
\text { ttest }\end{array}$ & & \\
\hline 1 & $\begin{array}{l}\text { Jevando Rizky } \\
\text { A }\end{array}$ & 58 & 61 & 3 & 9 \\
\hline 2 & Oktafian F.A & 67 & 69 & 2 & 4 \\
\hline 3 & $\begin{array}{l}\text { Kosman Ivan } \\
\text { C.H }\end{array}$ & 67 & 70 & 3 & 9 \\
\hline 4 & M. Adib. H. & 56 & 58 & 2 & 4 \\
\hline 5 & Aldno Bagus & 64 & 66 & 2 & 4 \\
\hline 6 & Bertnadius & 59 & 61 & 2 & 4 \\
\hline 7 & M. Fauzan & 66 & 68 & 2 & 4 \\
\hline 8 & M. Rayya & 70 & 72 & 2 & 4 \\
\hline 9 & M. Farel & 57 & 60 & 3 & 9 \\
\hline 10 & Gilang Fachrizal & 62 & 64 & 2 & 4 \\
\hline & $\mathrm{N}$ & 626 & 649 & 23 & 55 \\
\hline
\end{tabular}

Hasil dari data penelitian pretes dan postes dalam kelompok eksperimen terkumpul yang disajikan dalam bentuk tabulasi yang mempunyai jumlah skor pretes sebesar 626 , jumlah skor postes sebesar 649 , jumlah skor uji Beda (x) sebesar 23 serta $x^{2}$ sebesar 55 .
Tabel 2. Data hasil pretest dan posttest kelompok kontrol

\begin{tabular}{|c|c|c|c|c|c|}
\hline \multirow{3}{*}{ No } & \multirow{3}{*}{ Nama } & \multicolumn{2}{|c|}{$\begin{array}{l}\text { Tes Tinggi } \\
\text { Lompatan }\end{array}$} & \multirow{3}{*}{$\begin{array}{l}\text { Beda } \\
(\mathrm{x})\end{array}$} & \multirow{3}{*}{$x^{2}$} \\
\hline & & Pre & Pos & & \\
\hline & & test & ttest & & \\
\hline 1 & Bintang Rafif & 52 & 54 & 2 & 4 \\
\hline 2 & Adrianu Arfan & 50 & 51 & 1 & 1 \\
\hline 3 & Dony Gunawan & 49 & 51 & 2 & 4 \\
\hline 4 & Fakhri Oktavian & 55 & 57 & 2 & 4 \\
\hline 5 & Farhan Karunia & 43 & 45 & 2 & 4 \\
\hline 6 & $\begin{array}{l}\text { Nadhif } \\
\text { Nasrulloh }\end{array}$ & 57 & 59 & 2 & 4 \\
\hline 7 & Ranu Syahrizal & 48 & 49 & 1 & 1 \\
\hline 8 & $\begin{array}{l}\text { Fajar } \\
\text { Kurniawan }\end{array}$ & 44 & 46 & 2 & 4 \\
\hline 9 & Novansyah Dwi & 52 & 54 & 2 & 4 \\
\hline 10 & Fathur Rohman & 49 & 50 & 1 & 1 \\
\hline & $\mathrm{N}$ & 499 & 516 & 17 & 31 \\
\hline
\end{tabular}

Setelah data kelompok kontrol tabulasikan maka jumlah skor pretes sebesar 499, skor posttest sebesar 516 , skor (x) sebesar 17 serta $x^{2}$ sebesar 31. Setelah nilai kelompok eksperimen dan kelompok diketahui maka hasil data penelitian akan dianalisis dengan bertujuan untuk mengetahui perbedaan hasil dari kelompok eksperimen dan kelompok kontrol.

Hasil pengolahan data penelitian ini yang berjudul "Pengaruh latihan Tuck Jump terhadap Peningkatan Tinggi Lompatan Pada Pemain Bola Voli Putra SMA Intensif Taruna Pembangunan Surabaya" berdasarkan hasil analisis data menunjukkan nilai $t_{\text {hitung }} 2,86$ lebih besar dari nilai $t_{\text {tabel }}$ dengan taraf signifikan 5\% $(a=0,05)$ adalah 1,73. 
http://jurnal.unipasby.ac.id/index.php/stand/about/submissions jurnal.stand@unipasby.ac.id

Artinya bahwa metode yang digunakan oleh penulis dalam penelitian ini yaitu tuck jump memberikan pengaruh terhadap peningkatan tinggi lompatan pada pemain bola voli putra SMA Intensif Taruna Pembangunan Surabaya. Dapat disimpulkan hasil dari nilai $t_{\text {hitung }}>$

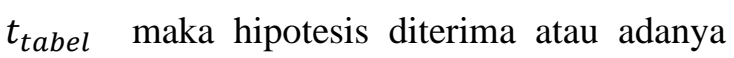
pengaruh latihan tuck jump terhadap peningkatan tinggi lompatan pada pemain bola voli putra SMA Intensif Taruna Pembangunan Surabaya.

Hasil dari pengolahan data dapat disimpulkan bahwa adanya peningkatan yang signifikan 5\% $(a=0,05)$ yang menunjukkan nilai $t_{\text {hitung }} 2,86$ lebih besar dari nilai $t_{\text {tabel }}$ 1,73. Artinya bahwa metode yang digunakan oleh peneliti adalah dengan adanya latihan Tuck Jump memberikan pengaruh terhadap kemampuan tinggi lompatan pada pemain bola voli putra SMA Intensif Taruna Pembangunan Surabaya. Maka hipotesis diterima.

Langkah-langkah yang dilakukan oleh peneliti sebelum menarik kesimpulan yaitu (1) dilakukan pretest bertujuan agar kemampuan tinggi lompatan dapat diketahui, (2) pemberian perlakuan latihan Tuck Jump sebanyak 5 kali pertemuan, (3) yang terakhir adalah kegiatan posttest yang bertujuan untuk mengetahui pengaruh peningkatan tinggi lompatan terhadap subjek yang diberikan perlakuan untuk mengetahui adannya pengaruh latihan Tuck Jump terhadap peningkatan tinggi lompatan dapat di buktikan dengan uji-t. Uji-t akan menampilkan besar nilai $t_{\text {hitung dan }}$ signifikasinya.

\section{KESIMPULAN}

Simpulan pada hasil penelitian tentang adanya pengaruh latihan Tuck Jump terhadap peningkatan tinggi lompatan dalam permainan bola voli putra dengan menggunakan perhitungan manual yang mendapatkan hasil

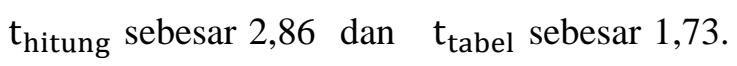
yang artinya $t_{\text {hitung }}$ lebih besar dari pada $t_{\text {tabel }}$. Dan menunjukkan bahwa ada pengaruh latihan tuck jump terhadap peningkatan tinggi lompatan. Maka hipotesis diterima.

Dilihat dari penelitian bahwa ada pengaruh latihan Tuck Jump, maka hendaknya peneliti olahraga maupun Pembina olahraga perlu untuk memberikan pelatiahan yang optimal untuk meningkatkan kemampuan tinggi lompatan dengan memberikan latihan yang efesien.

Bagi lembaga pendidikan hendaknya selalu memberikan dukungan serta metode pelatihan yang baik dan benar, sebagai salah satu upaya untuk meningkatkan kualitas atlet dalam bidang olahraga bola voli.

\section{REFERENSI}

Rosdiani, Dini., M.Pd. 2012. Dinamika olahraga dan pengembangan nilai. Bandung: Penerbit Alfabeta,cv.

Gaurav,Sigh, Sigh. 2010. Antrophometric Characteristics, Somatotyping and Body Composition of Volley Ball and BasketBall Player, Journal of Physical Education and Sport Management, Vol 1. No.3, Halaman 28-32 
Bompa, Tudor \& Haff, Gregory. 2009. Periodizaton Theory and Methodology of Training. Fifth Edition. United States: Human Kinetic.

Herrington, Lee., Myer., Gregory D. dan Munro Allan. 2013. "Intra dan intertester reliability of the tuck jump assessment". Journal of physical Therapy in Sport. No. 14 Pp. 152-155.

Sugiyono. 2016. Metode Penelitian Pendidikan; Pendektan Kuantitatif, Kualitatif, dan $R \& D$. Bandung: Alfabeta,cv

Maksum, Ali. 2009. Metode penelitian dalam olahraga. Surabaya: Fakultas Ilmu Keolahragaan. Universitas Negeri Surabaya.

Arikunto, Suharsimi. 2006. Prosedur Penelitian: Pendekatan Praktik. Jakarta : Rineka Cipta.

Maksum, Ali. 2009. Metode penelitian dalam olahraga. Surabaya: Fakultas Ilmu Keolahragaan. Universitas Negeri Surabaya. 